\title{
Yabancı dil Fransızca öğretimi ders kitabı "Le Nouveau Taxi 1"de A 1 düzeyi kültürel öğelerin sunumu
}

\section{Deniz DEMÍRKAN ${ }^{1}$}

APA: Demirkan, D. (2020). Yabancı dil Fransızca öğretimi ders kitabı “Le Nouveau Taxi 1"de A 1 düzeyi kültürel öğelerin sunumu. RumeliDE Dil ve Edebiyat Araştırmaları Dergisi, (Ö7), 541-556. DOI: $10.29000 /$ rumelide.811027.

\section{Öz}

Yabancı dil öğretmek/öğrenmek demek sadece dil bilgisi, kelime ve dil becerilerini öğretmek/öğrenmek demek değil, aynı zamanda o dilin kültürel öğelerini de öğretmek/öğrenmek demektir. Gerçek anlamda yabancı bir dili öğretmek, o dilini şekillendiren kültürünü öğretmekle mümkündür. Bu nedenle yabancı dili öğreten öğretmen aynı zamanda kültür öğretmenliği de yapar. Öte yandan, kültürü oluşturan unsurların çeşitli olması sebebiyle yabancı dil kültürünü oluşturan bütün öğelerin ders sırasında ve ders araçlarıyla aktarılması mümkün değildir. Kuşkusuz kültür aktarımının en önemli materyallerinden biri ders kitaplarıdır çünkü o dili konuşan toplum kaynaklıdır ve o dile ait kültürün taşıyıcılığını yapmaktadır. Kültürlerarası karşılaşma alanı olan yabancı dil öğretiminin verimli bir kültür iletimi aracı olabilmesi için de ders kitaplarındaki metinlerin bilinçli bir şekilde seçilmiş olması gerekmektedir. Nitekim dil öğretiminin başlıca amaçlarından biri de Diller için Avrupa Ortak Başvuru Metni (Öğrenme-ÖğretmeDeğerlendirme)'ne göre kültürel beceri kazanımı olarak yer almaktadır. Bu çalışmada yabancı dil olarak Fransızca öğretimi derslerinde kullanılan "Le Nouveau Taxi” setinin "Le Nouveau Taxi 1 Méthode de Français” ders kitabındaki kültürel öğelerin Ortak Başvuru Metni ölçütlerinden hareketle öğrenenlere nasıl aktarıldığı doküman incelemesi yöntemiyle ele alınmıştır. Çalışmanın eğitsel içeriğine serpiştirilen ve diyaloglara eşlik eden sosyokültürel öğeler, öğrenenlerin A 1 düzeyi öğrenme hedeflerine uygun biçimde tasarlanmış ve eğitsel içeriğin, hedef kültürün aktarımını gerçekleştirmede yeterli olduğu düşüncesine ulaşılmıştır.

Anahtar kelimeler: Ders kitabı, kültür, kültür aktarımı, kültürel öğeler, yabancı dil öğretimi

\section{Presentation of cultural items in French A 1 language level in foreign language French teaching coursebook "Le nouevau Taxi 1 methode de Français"}

\begin{abstract}
Teaching / learning a foreign language means not only teaching / learning grammar, vocabulary and language skills, but also teaching / learning the cultural elements of that language. Teaching a foreign language in a literal manner is possible by teaching the culture that shapes that language. For this reason, the teacher who teaches a foreign language is also a cultural teacher. Due to the diversity of the elements that make up the culture, it is not possible to transfer all the items that make up the foreign language culture during the course and with the course tools. Undoubtedly, one of the most important materials of cultural transfer is coursebooks as those are originated from the society that speaks that language and carries the culture of that language. For foreign language teaching, the texts in the coursebooks must be consciously selected; which is an efficient means of cultural transmission in the area of cross-cultural encounters. As a matter of fact, one of the main
\end{abstract}

Dr. Öğr. Üyesi, Mersin Üniversitesi, Fen-Edebiyat Fakültesi, Mütercim-Tercümanlık Bölümü (Mersin, Türkiye), ddemirkan@mersin.edu.tr, ORCID ID: oooo-00o2-1115-3411 [Makale kayıt tarihi: 28.07.2020-kabul tarihi: 20.10.2020; DOI: 10.29000/rumelide.811027] 
Presentation of cultural items in French A 1 language level in foreign language French teaching coursebook "Le nouevau Taxi 1 methode de Français" / D. Demirkan (pp. 541-556)

\begin{abstract}
objectives of language teaching is cultural skill acquisition according to the Common European Framework (CEF) of Reference for Languages (Learning-Teaching-Evaluation). In this study, how the cultural elements in the "Le Nouveau Taxi 1 Méthode de Français" textbook used in the teaching of French as a foreign language was transferred to the learners based on the criteria of the Common Application Text was examined. The sociocultural elements, which are interspersed with the educational content of the study and accompany the dialogues, have been designed in accordance with the A 1 level learning objectives of the learners and it has been thought that the educational content is sufficient to carry out the transfer of the target culture.
\end{abstract}

Keywords: Coursebook, culture, cultural transfer, cultural elements, foreign language teaching

\title{
Giriş
}

Ülkeler arasında sınırların kalktığı, rekabetin hızlandığı, iletişim araçlarıyla anında her noktasına ulaşılan dünyamızda yabancı dil öğrenmenin gerekliliği ve zorunluluğu yadsınamaz. Bu bağlamda, Avrupa Birliği’nin öngördüğü çok dillilik konusunu hayata geçirmek oldukça yerinde bir karar olmuştur çünkü bilgi, çok dilli bir biçimde çağın imkânları sayesinde çok hızlı yayılmaktadır. Yani hızla gelişen bilgi teknolojileri sayesinde bilgi, dünyanın her köşesine kolayca ulaşabilmekte ve oturduğumuz yerden teknolojik araçları kullanarak dünyanın öbür ucundaki bir bilgiyi kolayca elde edebilmekteyiz (Kuşçu ve Karan, 2017:1-2). Küresel düzeyde ortaya çıan bu teknolojik gelişmeler hızlı bir şekilde toplumları etkilemekte ve bu sayede bir toplumda ortaya çıkan değişiklik diğer uluslara kolaylıkla aktarılabilmektedir. Bu süreç sadece bilginin akışını kolaylaştırmakla kalmayıp, kültür ve iletişim kalıplarının da toplumlar arasında transferini hızlandırmaktadır. Böylece küreselleşen dünyada yabancı dil öğrenmenin ve öğretmenin önemi tartışılmaz bir gerçeklik olmakla birlikte her türlü iletişim ve bilgi edinme süreçlerinde yabancı dil bilmek zaruriyet arz etmektedir. Bu konuda birçok ülkenin milli eğitim sisteminde birden fazla dil bilmek amaçlanırken ülkemizde de ilköğretim düzeyinde birinci yabancı dil, ortaöğretim aşamasında da seçmeli ikinci yabancı dilin öğretilmektedir. Ancak yabancı dili kullanmayı bir araç olarak görmek dil öğretiminin en önemli noktalarından biridir. Çünkü milleti oluşturan kültürel değerlerin bir arada tutulmasına yarayan dil, ulusların gelişip, tarihten aldıkları tecrübeleri ve medeniyetleri gelecek nesillere aktarıp egemenliklerini sağlamaya ve sürdürmeye yarayan bir araçtır.

\section{Dil ve kültür}

Çalışmayı daha iyi bir biçimde şekillendirmek için bazı kavramları iyice tanımlamak gerekmektedir. Buna göre, alan yazında dil ve kültür üzerine söylenmiş onlarca tanım mevcuttur. Türk Dil Kurumu Türkçe Sözlüğe göre: "İnsanların düşündüklerini ve duyduklarını bildirmek için kelimelerle veya işaretlerle yaptıkları anlaşma, lisan, zeban; bir çağa, bir gruba, bir yazara özgü söz dağarcığı ve söz dizimi; belli mesleklere özgü dil; düşünce ve duyguları bildirmeye yarayan herhangi bir anlatım aracı. (http://www.tdk.gov.tr) olarak tanımlanmaktadır. Benzer bir biçimde "Dil nedir?" diye sorulduğunda Uygur'un verdiği yanıt oldukça anlamlıdır. "Kimse bana sormayınca biliyorum. Birine açıklamaya kalkınca da, bilmiyorum” (Uygur, 1994:11) diyerek dil sözcüğünü açıklamıştır.

Uluslar dillerini ve kültürlerini yüzyıllardır süregelen tecrübeleri sonucunda yoğurmuşlardır. Bu esnada dil ve kültür, akan bir nehir gibi, içinden geçtiği her topraktan bazı unsurları bünyesine katarak zenginleşmiştir. Hatta her uygar ulusun konuşma ve yazı dili, karşılaştı̆̆ı diğer uygarlıklardan ödünç 
alınan kültürel özellikler, kelimeler, deyimler, vb. öğelerle doludur. Bu bakımdan her ulusun dili, o ulusun çağlar boyunca yaşadığı tarihin adeta özetidir (Kaplan, 1982:187-188).

Aksan’a (2003) göre dil düşünce, duygu ve isteklerin, bir toplumda ses ve anlam yönünden ortak olan öğeler ve kurallardan yararlanılarak başkalarına aktarılmasını sağlayan, çok yönlü ve çok gelişmiş bir dizgedir (55).

Batılı kaynaklarda da dille ilgili birçok tanım bulunmaktadır. Saussure’ün bu konudaki görüşlerine göre, "Dil, varlığını yalnızca, topluluk üyeleri arasında yapılmış bir tür sözleşmeye borçludur. Dil o denli apayrı bir şeydir. Sözden ayrı olan dil ondan bağımsız biçimde incelenebilecek bir konudur. Bir göstergeler dizgesidir. Dil de söz gibi somut niteliklidir. Toplumun onayladığı ve tümü dili oluşturan birleştirmeler, özeği beyinde yer alan gerçekliklerdir" (çev. Vardar, 1998: 44-45). Sonuç olarak dil, insanlar arasında iletişimi sağlayan mucizevî bir güce sahiptir. Çünkü insan yapıp ettiklerini, düşündüklerini, duygularını kısacası kendini bir şekilde ifade etmek ister. Bu, insan olmanın özelliğidir. Ayrıca toplumsal olarak da ele alındığında, bir ulusu oluşturan en önemli unsurlardan biridir. Bu yönüyle de toplumların kültürü, örf ve adetlerinde ve yaşam biçimlerinde dillerinin etkisi damgasinı vurur.

Benzer bir biçimde alan yazında kültür kavramıyla ilgili birçok tanım yapılmıştır. Bu konuda Türk Dil Kurumu Türkçe Sözlükte "kültür” kavramıyla ilgili tanımlardan birkaçı şöyledir:

Tarihsel, toplumsal gelişme süreci içinde yaratılan bütün maddi ve manevi değerler ile bunları yaratmada, sonraki nesillere iletmede kullanılan, insanın doğal ve toplumsal çevresine egemenliğinin ölçüsünü gösteren araçların bütünü, hars, ekin; bir topluma veya halk topluluğuna özgü düşünce ve sanat eserlerinin bütünü; muhakeme, zevk ve eleştirme yeteneklerinin öğrenim ve yaşantılar yoluyla geliştirilmiş olan biçimi; bireyin kazandığı bilgilerdir.

Etimolojik olarak kültür sözcüğü, Latince "cultura” sözcüğünden dilimize geçmiştir. Bu kelime toprağı ekip biçmek, sürmek, tarım anlamlarına gelmektedir. (...) Fransızca’da “culture” sözcüğünün uygarlık karşıllğında "Academie Française” sözlüğüne geçmesi ancak 1932'de gerçekleşen bir durumdur. Ayrıca Güvenç (1972) kültür sözcüğü dört biçimde ifade etmiştir. Buna göre kültür, bilim alanında uygarlık; beşeri alanda eğitim sürecinin ürünü; estetik alanda güzel sanatlar ve maddi (teknolojik) ve biyolojik alanda üreme, tarım, ekin, çoğaltma ve yetiştirme.” olarak belirtilmiştir (96). Öte yandan kültür kavramını, insan zekâsının oluşumu, gelişimi, geliştirilmesi ve yüceltilmesi anlamında ilk kez kullanan kişi ünlü Fransız düşünür Voltaire’dir (Kasır,1993: 16-17; Güvenç,1972: 96-99).

Benzer bir biçimde UNESCO'da kültür kavramını şöyle tanımlanmaktadır: Bir insan topluluğunun kendi tarihi gelişim süreci konusunda sahip olduğu bilinç demektir. İnsanoğlu, söz konusu bu tarihi gelişim bilincinin ışı̆̆ında varlığını devam ettirme azmini gösterir ve gelişmesini sağlar (Arpacı, 1985'den akt. Ylldız, 2005:4)

Günümüzde küreselleşen dünyada bireylerin yaşam tarzları ve kültürel öğeleri, ülkelerin sinırlarını aşmakta, çok uzak ülkelerde bile benzerlikler göstermektedir. Bu konuda Wolfgang Welsh'in tespiti oldukça önemlidir. Ona göre bir ekonomist, bir akademisyen ya da bir gazeteci bundan böyle Alman, Fransız ya da Türk değildir, belki Avrupalı ya da tüm dünyalıdır (akt. Ünalan, 2002:77).

Tüm bu tanımlardan ve açıklamalardan hareketle, gerek yabancı dil öğretiminde gerekse yabancı dil öğreniminde kültür, dil için inanılmaz bir kaynak; dil de kültür için vazgeçilmez bir araçtır (Göçer, 2012:57). 
Presentation of cultural items in French A 1 language level in foreign language French teaching coursebook "Le nouevau Taxi 1 methode de Français" / D. Demirkan (pp. 541-556)

\title{
Kuramsal çerçeve
}

Çalışmanın amacı, yabancı dil olarak Fransızca öğretiminde kullanılan“Le nouveau Taxi 1 Méthode de Français” ders kitabındaki kültürel öğelerin dil öğretimine ne kadar katkı sağladığı tespit etmek ve bu öğelerin Diller İçin Avrupa Ortak Başvuru Metni (OBM) ölçütlerine göre hazırlanıp hazırlanmadığını belirlemektir. Bu bağlamda OBM’de de ifade edildiği gibi:

\begin{abstract}
"Dil öğrenmeyi de içine alan dil kullanımı, hem genel anlamda yetenekler hem de özel olarak iletişimsel dil yetenekleri geliştiren bireyler ve sosyal aktörler olarak şahıslar tarafindan gerçekleştirilen eylemleri kapsar. İnsanlar, görevleri yerine getirmek için en uygun görünen stratejileri harekete geçirerek, çok özel alanlardaki temalarla ilgili metin üretme ve/veya almaya yönelik dil süreçlerini içeren dil etkinliklerine katılmak için çeşitli bağlamlarda ve şartlarda ve çeşitli sınırlamalar altında ellerindeki yeteneklere başvururlar. Katılımcıların bu eylemleri yönetmeleri sonucunda yetenekleri ya pekiştirilmiş olur ya da değişikliğe uğrar.” İlkesine bağlı olarak tasarlanmıştır. (Diller İçin Avrupa Ortak Başvuru Metni, 2000:7).
\end{abstract}

Çalışmamızın temel öğesi olan "Le Nouveau Taxi 1" seti, Fransızcayı yabancı dil olarak yeni öğrenmeye başlayan yetişkinlere ve daha büyük ergenlere hitap edecek bir biçimde tasarlanmıştır. Dil öğrenme düzeyi olarak, başvuru metninde belirtilen üç düzeyden ilki olan A1 Düzeyine (Giriş ya da Keşif Breakthrough) göre içerik oluşturulmuştur. Ayrıca eğitsel içerik, öğrenenlerin DILF A1 ve DELF A1 sınavlarına hazırlanmalarına olanak sağlar biçimdedir. Kitap 90 ders saati içinde öğrenenlerin 4 temel dil becerilerini (dinlediğini anlama, okuduğunu anlama, sözlü anlatım ve yazılı anlatım) edinebilmelerini hedeflemektedir.

“Le nouveau Taxi 1 Méthode de Français” serisi, 144 sayfalık öğrenci ders kitabı, 224 sayfalık öğretmen kılavuz kitabı, 96 sayfalık öğrenci alıştırma kitabı, DVD-ROM ve ses kayıtları için olan 2 tane CD'den oluşmaktadır. Materyal Fransız uzmanlar Guy Capelle ve Robert Menand tarafından yazılmış ve 2009 tarihinde Hachette Livre tarafından basılmıştır.

Kitabın eğitsel içeriği, eylem odaklı yaklaşım (approche actionnelle) doğrultusunda şekillendirilmiş temalardan oluşmaktadır. Toplamda 9 üniteden oluşan kitapta; her bir ünite de 4 ders olmak üzere toplam 36 ders, 3 çeşit DELF ve DILF değerlendirme etkinlikleri bulunmaktadır. Her bir dersin içeriğinde; tematik kelime listesi, dinleme kayit dökümü (transkripsiyon), dil bilgisi özeti ile fonetik alfabe, fiil çekim tablosu, çok dilli bir sözlük, Fransızca konuşulan dünya haritası ile Fransa'nın turizm haritası yer almaktadır. Ayrıca öğretmen kitabında 9 ünitenin her bir ünitesi için 2 tekrar formu ve cevap anahtarı olmak üzere toplamda 27 tane çoğaltılabilir formla birlikte her bir ünite için toplamda 9 yetenek testi bulunmaktadır.

\section{Yöntem}

Çalışmanın içeriği, doküman incelemesi tekniğiyle elde edilmiştir. Doküman incelemesi, araştırılması hedeflenen olay veya olgular hakkında bilgi içeren yazllı materyallerin analizini kapsamaktadır (Yıldırım ve Şimşek, 2013:217). Çalışmada, "Le nouveau Taxi 1 Méthode de Français" kitabının Fransızcayı öğretirken kültürel öğelere ne kadar yer verdiği üzerinde durulmuştur. Söz konusu kültürel öğeler, OBM'de yer alan "Sosyokültürel Bilgi" alt başlı̆̆ında betimlenmiş olan maddelere göre yorumlanmış ve değerlendirmeler yapılmıştır. Buna göre,,öncelikle Avrupa Konseyi tarafından oluşturulmuş Ortak Başvuru Metni incelenmiş,metnin "Genel Yetenekler" Bölümü, "Bildirimsel Bilgi" alt başlı̆̆ındaki"Sosyokültürel Bilgi” bölümünde bulunan liste temel alınarak "Le nouveauTaxi 1 Méthode de Français” ders kitabı incelenmiştir (OBM,2000:97-98). OBM'de yer alan ve kültürel öğelerin öğretimini gösteren liste şöyledir:

\footnotetext{
Adres $\mid$ Address 
1. Günlük yaşamdan örnekler,

- Yiyecek-içecekler, yemek zamanları, sofra adabı

- Ulusal bayramlar,

- Çalışma saatleri ve uygulamaları,

- Boş zaman etkinlikleri (hobiler, spor, okuma alışkanlıkları, medya)

2. Yaşam biçimlerinden örnekler,

- Yaşam standartları (bölgesel, sınıfsal ve etnik farkllılılar),

- Barınma olanakları,

- Sosyal yardım düzenlemeleri

3. Kişiler arası ilişkilerden (güç ve çıkar ilişkileri dâhil) örnekler,

- Toplumdaki sınıf yapısı ve sınıflar arası ilişkiler,

- Cinsler arası ilişkiler,

- Aile yapısı ve aile bireyleri arasındaki ilişkiler,

- Nesiller arası ilişkiler,

- İş ortamındaki ilişkiler,

- Toplum ile polis ve resmî görevliler arasındaki ilişkiler,

- Irk ve toplum ilişkileri,

- Siyasi ve dini gruplar arasındaki ilişkiler,

4. Değerler, inanışlar ve tutumlar, vb. konularla ilgili örnekler,

- Sosyal sinif,

- Meslek grubu (akademik, yönetici, sosyal hizmet, usta ve el emekçisi),

- Sağlık (kazanılmış ve kalıtsal)

- Bölgesel kültür,

- Güvenlik,

- Kurumlar,

- Gelenek ve sosyal değişim,

- Tarih; özellikle ikonlaşmış tarihi kişi ve olaylar,

- Azınlıklar (etnik ve dini),

- Ulusal kimlik,

- İdeolojiler,

- Yabancı üniversiteler, yabancı kişiler,

- Sanat (müzik, görsel sanatlar, edebiyat, drama, popüler müzik

- $\quad$ Mizah (gülmece)

5. Beden diline ilişkin (OBM bölüm 4.4.5) öğeler. Bilindiği gibi beden diline hükmeden örf ve âdetlerin bilgisi kullanıcının/öğrenenin sosyokültürel yeteneğinin bir bölümünü oluşturur. $\mathrm{Bu}$ 
Presentation of cultural items in French A 1 language level in foreign language French teaching coursebook "Le nouevau Taxi 1 methode de Français" / D. Demirkan (pp. 541-556)

bağlamda bu bölümdeki dil etkinlikleri genellikle yüz-yüze sözlü iletişim biçimlerine eşlik eden pratik hareketlerle beden dili kullanımlarını içerir.

6. Misafirlik vb. gibi durumlardaki gelenek görenekler,

- Dakiklik

- Hediye

- Giyecek

- Yiyecek ve içecekler

- Davranış ve söyleyiş âdetleri

- Kalış (ziyaret) süresi

- Vedalaşma

7. Törensel öğeler,

- Dini tören ve ayinler

- Doğum, evlilik, ölüm

- Halka açlk gösteri ve törenlerde dinleyici ve seyirci davranışları (tavırları)

- Kutlamalar, festivaller, danslar, disko, vb.

\section{Bulgular ve yorumlar}

"Le nouveau Taxi 1 Méthode de Français" ders kitabındaki kültürel öğelerin öğrenenlere nasıl aktarıldığını incelemek için OBM’ye göre sıralanmış bu ölçütler, ders kitabı içeriğinde taranmış ve tabloya dökülmüştür. Her bir öğe ait olduğu alanda gruplandırılmıştır. Çözümlenen verilerden elde edilen bulgular sayısal olarak Tablo 1'de verilmiştir.

Tablo 1. "Le nouveau Taxi 1" kitabındaki kültürel içerik ve hangi sosyokültürel amacı karşıladığı.

\begin{tabular}{|l|l|l|}
\hline & Sosyokültürrel İçerik & $\begin{array}{l}\text { Sosyokülttürel } \\
\text { Bilgi No.: }\end{array}$ \\
\hline $\begin{array}{l}\text { Ünite 1 } \\
\text { Ders 1-4 }\end{array}$ & $\begin{array}{l}\text { Karşlaşma ve tanışma } \\
\text { Dünyada Frankofoni }\end{array}$ & $1,2,3,4,6$ \\
\hline DVD & $\begin{array}{l}\text { Video Röportaj: Paris Şehri: } \\
\text {-Karşılaşma ve tanışma } \\
\text {-Paris' i keşfetmek }\end{array}$ & $1,2,3,4,5,6$ \\
\hline $\begin{array}{l}\text { Ünite 2 } \\
\text { Ders 5-8 }\end{array}$ & $\begin{array}{l}\text { Konut (koşulları) } \\
\text { Alşveriş } \\
\text { Sanat ve Sinema: birkaç Fransız sanatçı }\end{array}$ & $1,3,4,6$ \\
\hline DVD & $\begin{array}{l}\text { Video Röportaj: Çiçekler: } \\
\text {-Mağazadan ve internet üzerinde alışverişler } \\
\text {-Çiçek ticareti dünyası }\end{array}$ & $1,3,4,5,6$ \\
\hline $\begin{array}{l}\text { Ünite 3 } \\
\text { Ders 9-12 }\end{array}$ & $\begin{array}{l}\text { Fransızların çevresi } \\
\text { Bir Fransız șehri olan Marsilya'da turistik keşif ve Fransa'nın } \\
\text { denizaşırı illerinden biri olan Martinik keşfi }\end{array}$ & $1,3,4$ \\
\hline DVD & $\begin{array}{l}\text { Video Röportaj: Réunion Adası: } \\
\text {-Ulaşım araçları: Paris Metrosu }\end{array}$ & $1,3,4,5$ \\
\hline
\end{tabular}




\begin{tabular}{|c|c|c|}
\hline $\begin{array}{l}\text { Ünite } 4 \\
\text { Ders 13-16 }\end{array}$ & $\begin{array}{l}\text { Günlük Hayat } \\
\text { Spor }\end{array}$ & $1,2,3,4$ \\
\hline DVD & $\begin{array}{l}\text { Video Röportaj: Aveyron şehri: } \\
\text {-Turizm acentesinde karşllama ve hizmet bedelleri } \\
\text {-Spor, eğlence merkezleri ve spor tesisler }\end{array}$ & $1,2,3,4,5$ \\
\hline $\begin{array}{l}\text { Ünite } 5 \\
\text { Ders } 17-20\end{array}$ & $\begin{array}{l}\text { Kıyafet, gıda ve içecek alışverişler alışkanlıkları } \\
\text { Fransa'da resmi ve dini kutlamalar (tatiller) }\end{array}$ & $1,3,4,6,7$ \\
\hline DVD & $\begin{array}{l}\text { Video Röportaj: Resmi ve dini kutlama dekorasyonları: } \\
\text {-Noel kutlaması dekorasyonları (şehirlerde ve büyük mağazalarda) } \\
\text {-Noel arifesi yemeği } \\
\text {-Akşam yemeği hazırlığı ve arkadaşları karşılama }\end{array}$ & $1,3,4,5,6,7$ \\
\hline $\begin{array}{l}\text { Ünite } 6 \\
\text { Ders 21-24 }\end{array}$ & $\begin{array}{l}\text { Ritüel (günlük ve alışkanlık olan) davranışlar } \\
\text { İş hayatı }\end{array}$ & $1,3,4,6,7$ \\
\hline DVD & $\begin{array}{l}\text { Video Röportaj: İş̧ arama: } \\
\text {-İş dünyası } \\
\text {-İş görüşmesi (mülakatı) }\end{array}$ & $1,3,4,5,6,7$ \\
\hline $\begin{array}{l}\text { Ünite } 7 \\
\text { Ders } 25-28\end{array}$ & $\begin{array}{l}\text { Hayat standardı, yaşam ortamı } \\
\text { Zevkler ve tatiller }\end{array}$ & $1,2,3,4,6$ \\
\hline DVD & $\begin{array}{l}\text { Video Röportaj: Languedoc-Roussillon Bölgesi: } \\
\text {-Fransızların tatil alışkanlıkları } \\
\text {-Fransız bir ailenin tatile çıkmadan önceki son hazırlıkları } \\
\text { - Fransa'nın güneyinde bulunan bir bölge olan Languedoc- } \\
\text { Roussillon'da turistik, kültürel ve sportif keşfi } \\
\text {-Farklı spor aktivitelerin tanıtımı }\end{array}$ & $1,2,3,4,5,6$ \\
\hline $\begin{array}{l}\text { Ünite } 8 \\
\text { Ders 29-32 }\end{array}$ & $\begin{array}{l}\text { Sosyokültürel ilişkiler } \\
\text { Fransa'nın sembolleri }\end{array}$ & $1,2,3,4,6,7$ \\
\hline DVD & $\begin{array}{l}\text { Video Röportaj: 1950'li yıllarda: } \\
\text {-Hatıralar } \\
\text {-Yeni başlayan bir aşkın hikâyesi } \\
\text {-1950'li yllarda Paris'te yaşam }\end{array}$ & $1,2,3,4,5,6,7$ \\
\hline $\begin{array}{l}\text { Ünite } 9 \\
\text { Ders } 33-36\end{array}$ & $\begin{array}{l}\text { Gelecek } \\
\text { Projeler }\end{array}$ & $1,2,3,4,6$ \\
\hline DVD & $\begin{array}{l}\text { Video Röportaj: Küçük işler: } \\
\text {-Gençlerin kaygıları: Bakalorya sınavı, ehliyet sınavı, iş, vb. } \\
\text {-Mevsimlik/küçük bir yaz işi arayışı }\end{array}$ & $1,2,3,4,5,6$ \\
\hline
\end{tabular}

Avrupa Konseyi tarafından 7 başlık altında belirlenmiş olan sosyokültürel öğeler, Tablo 1'de de görüldüğü gibi yetişkinlere yönelik tasarlanan A1 seviyesindeki "Le NouveauTaxi1 Méthode de Français” ders kitabının içeriğine yoğun şekilde serpiştirilmiştir. Örneğin kitabın birinci resmi sanatçı Carla Bruni'nin Fransız "Madame" dergisine (Le NouveauTaxi 1, 2009: 12) verdiği bir pozla başlamaktadır. Hemen yan sayfadaki dördüncü resimde ise, dünyaca ünlü Edith Piaf'n hayat hikâyesini anlatan "Minik Serçe" (La vie en rose) filminden tanıdığımız başrol oyuncusu Marion Cotillard resmi yer almaktadır. Kitabın birinci dersinde yer alan dört diyalogda, "sen" ve "siz" kalıplarının öğretilmesi amaçlanmıştır. "Kişiler arası ilişkiler” kısmında belirtilen amaca uygun olarak oluşturulmuş diyaloglarda, öğrenenin sosyal bir çevrede kişilere nasıl hitap etmesi gerektiği bilgisi verilmiştir. Diğer derslerde ise dünyada hangi ülkelerin Fransızca konuştuğu, başka bir deyişle 

methode de Français" / D. Demirkan (pp. 541-556)

"Frankofoni” dediğimiz kavram ele alınmıştır. Fransızca öğrenen ve farklı kültürlere sahip kişilerin, önceden "mektup arkadaşlığı", günümüzde ise "elektronik posta" aracılığıla internet ortamında iletişim kurabilecekleri vurgulanmıştır. Örneklerde de olduğu gibi çalışmada oldukça fazla sayıda kültürel öğeye yer verilmiştir. Öte yandan çok fazla görüntü ya da kültürel öğeyi incelemek yerine her bir ünitede, alanla ilgili belirgin özelliklerin gösteren örnek görüntülere de yer verilmiştir. Örneğin, "günlük yaşam”, "yaşam şartları", "kişiler arası ilişkiler”, "değerler, inanışlar ve tutumlar” ve "sosyal adetler” gibi özelliklerin özeti olabilecek dördüncü dersin sayfa görüntüsü şu şekildedir (Görüntü 1).

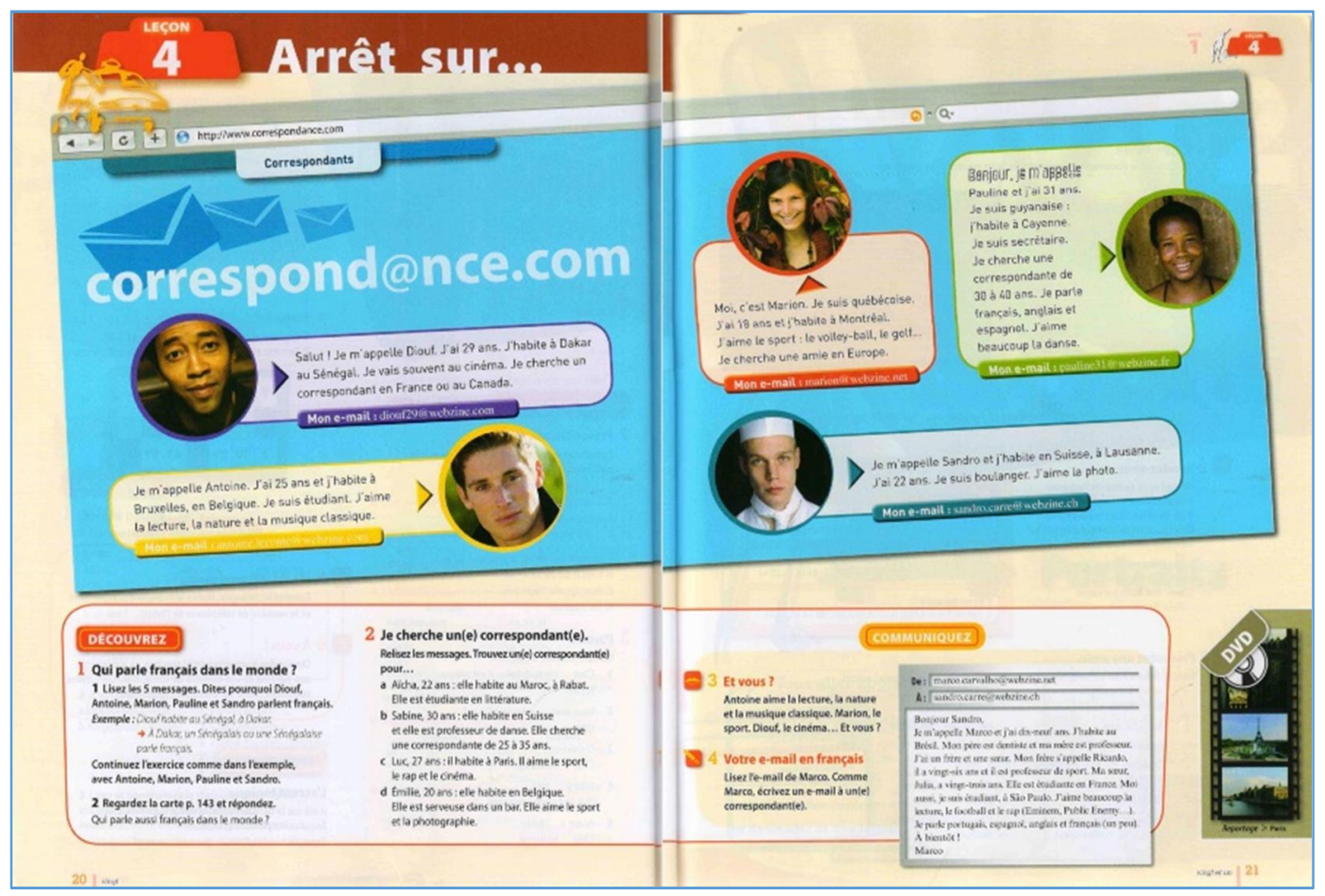

Görüntü 1. “Correspondance.com”durağı (Le Nouveau Taxi 1, 2009:20-21).

İkinci ünitenin ilk dersinde, Mélanie'nin odası resmedilmiştir. "Değerler, inanışlar ve tutumlar" da yer alan "kurumlar" ise jandarma karakolunda geçen bir diyalogla örneklendirilmiştir. Daha sonraki derste ise, günlük hayatımızda ve her kültürde önemli bir yere sahip olan "alışveriş" konusuna üzerinde durulmuştur. Mağazadan veya internet üzerinden alışveriş yapma ile ilgili diyaloglar yer almaktadır. Son derste, "Sanatçllar Köşesi”nde Fransız yaşamının önemli bir özelliği olan sanata ağırlık verilmiştir. Edith Piafın hayat hikâyesini anlatan "Minik Serçe” (La vie en rose) filminden kareler yer almaktadır. Bu dersteki yer alan alıştırmada, özellikle değişik sanat dallarındaki önemli isimler ve meslekler vurgulanmıştır. Örneğin, 20. yüzyılın en önemli ressamlarından Henri Matisse ve Fransız heykeltıraş Camille Claudel, 20. yüzyılın en önemli Fransız bestecilerinden Claude Debussy, Fransız romancı Colette, İtalyan asıllı Fransız şair, yazar ve sanat eleştirmeni olan Guillaume Apollinaire bunlardan sadece birkaçıdır. Son olarak ise Fransız şair ve senarist Jacques Prévert’in şiir derlemesindeki kelime oyunlarıyla büyük yankı bulan Paroles'den « Alicante » adlı şiiri yer almaktadır (Görüntü 2).Görüldüğü gibi içerikte kullanılan tüm kültürel öğeler yetişkin öğrenenlere hitap edecek nitelikte içerikte sunulmuştur. 


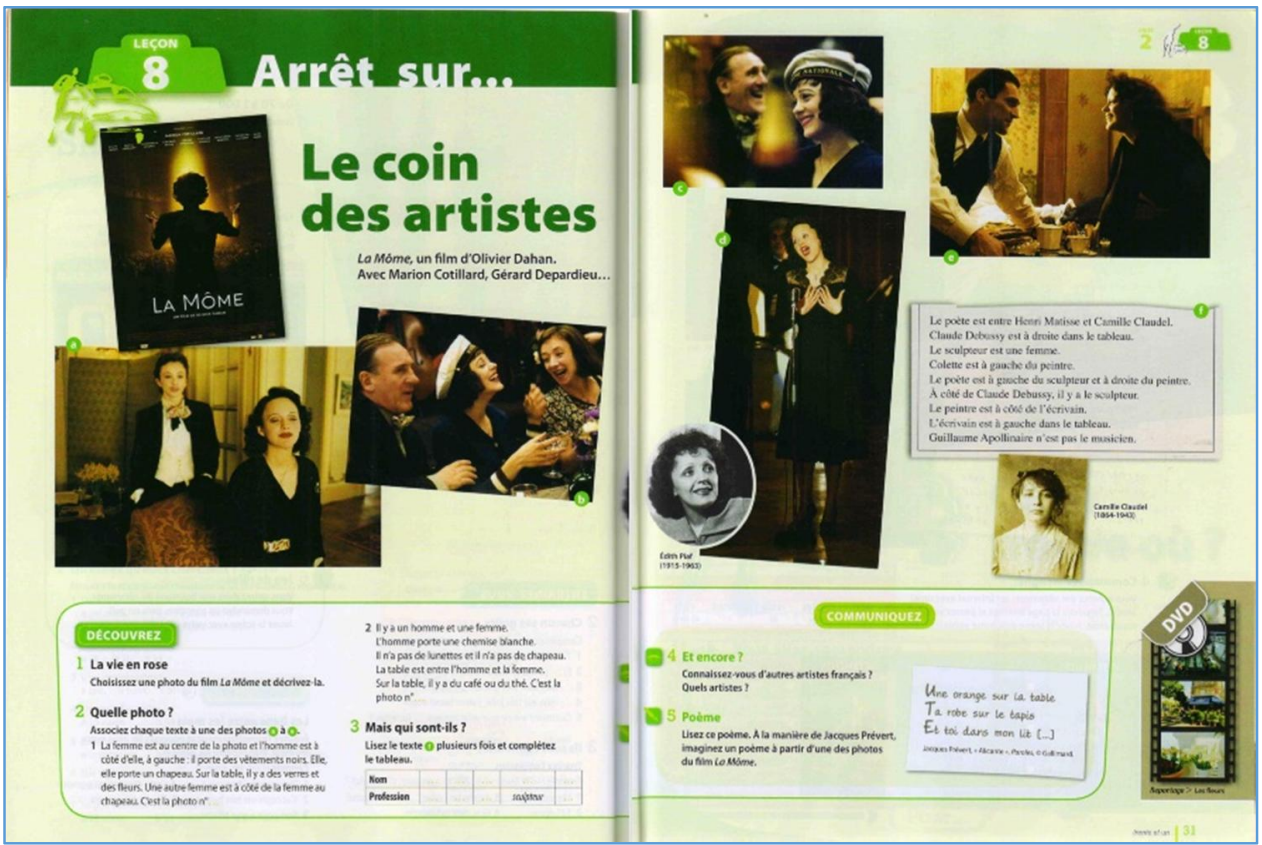

Görüntü 2. "Sanatçılar Köşesi” Durağı (Le Nouveau Taxi 1, 2009: 30-31)

Üçüncü ünitede gazete veya internet ilanlarına yer verilmiştir. Bu çerçevede ev kiralama ilanı örnek resimlerle anlatılmaya çalışılmıştır. Şehir hayatının tanıtılması amacıyla "Louvre Müzesi”ne ziyaret edecek birine bir planla birlikte bir diyalog eşlik etmektedir. Diyalogda ve planda Paris’te bulunan önemli tarihi yapıt isimleri ve sokak isimleri yer almaktadır ("Louvre Müzesi”, "Opera Binası", “Concorde Meydanı, Catherine de Medici tarafından 1564'te Tuileries Sarayı'nın bahçesi olarak yaratılan ve bir kamu bahçesi olan "Tuileries Bahçesi”, "Piramit”, vb., Opera caddesi, Rivoli Sokağı, Richelieu sokağı, Vendome meydanı, özgürlük caddesi, vb.). Hatta Fransızların günlük yaşamlarında önemli yere sahip olan (metro, tren ve bisiklet (Vélib: kiralık bisikletler) ulaşım araçları da bu konuda işlenmiştir. Ünitenin son dersinde ise öğrenci ve turizm kenti olan Fransa'nın ikinci büyük kenti Marsilya işlenmiştir (Görüntü 3). 
Presentation of cultural items in French A 1 language level in foreign language French teaching coursebook "Le nouevau Taxi 1 methode de Français" / D. Demirkan (pp. 541-556)

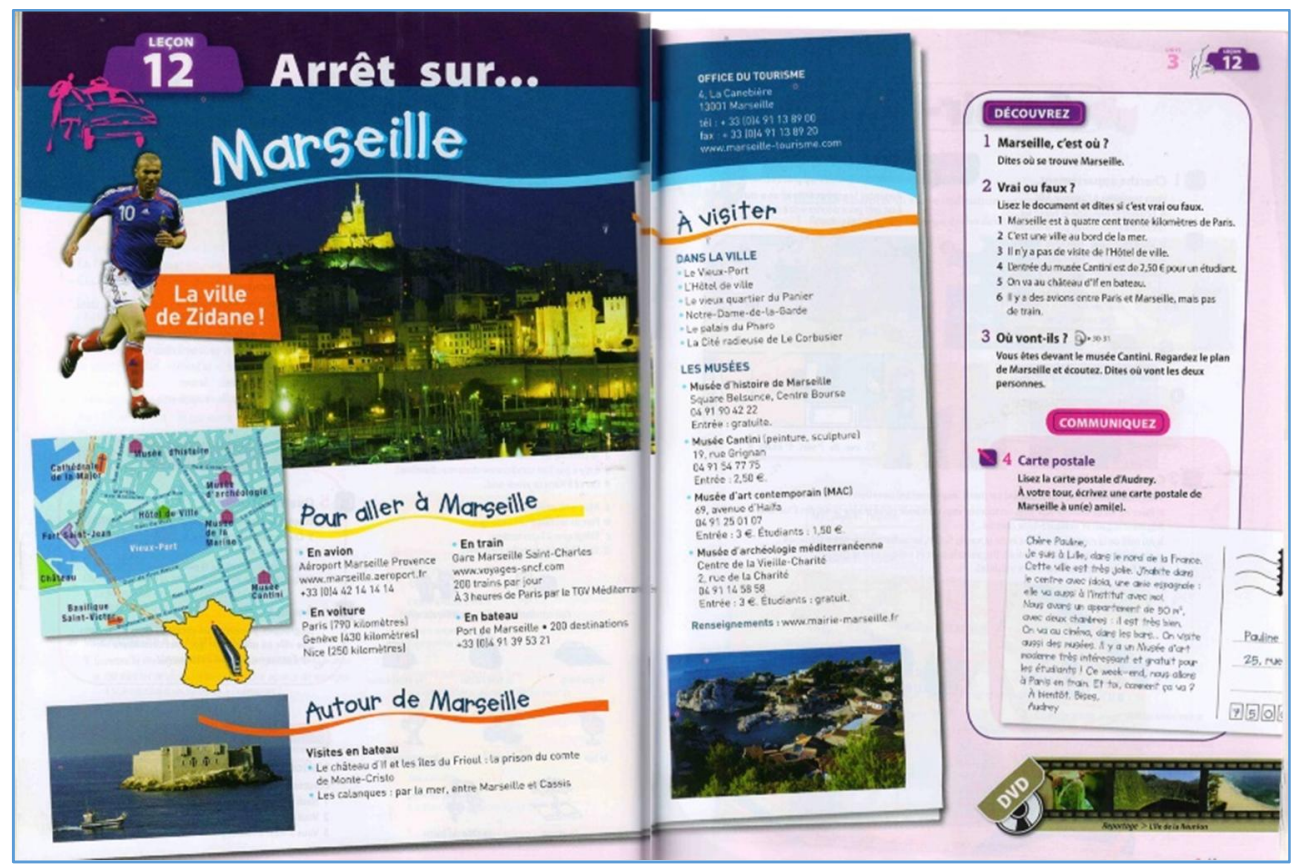

Görüntü 3. "Marseille” Durağı (Le Nouveau Taxi 1, 2009: 40-41).

Dördüncü ünitede Fransızların günlük hayatında önemli bir yere sahip olan yüksek hızlı tren (TGV) ile ilgili bir rezervasyon diyalogu ve Paris Kuzey Garı resmine yer verilmiştir. 15. Derste günlük yaşam içerisinde yapılan boş vakit etkinlikleri, spor ve günlük yaşam etkinliklerinden bahsedilmiştir. Örneğin ev süpürmek, kahvaltı hazırlamak, alışveriş yapmak, televizyon seyretmek, koşu yapmak, arkadaşlarla dışarı çımak, vb. Son derste ise olimpiyat, dünya ve Avrupa şampiyonu olan Fransız yüzücü Laure Manaudou'nun bir günü içerisinde neler yaptı̆̆ından bahsettiği röportaj yer almaktadır.

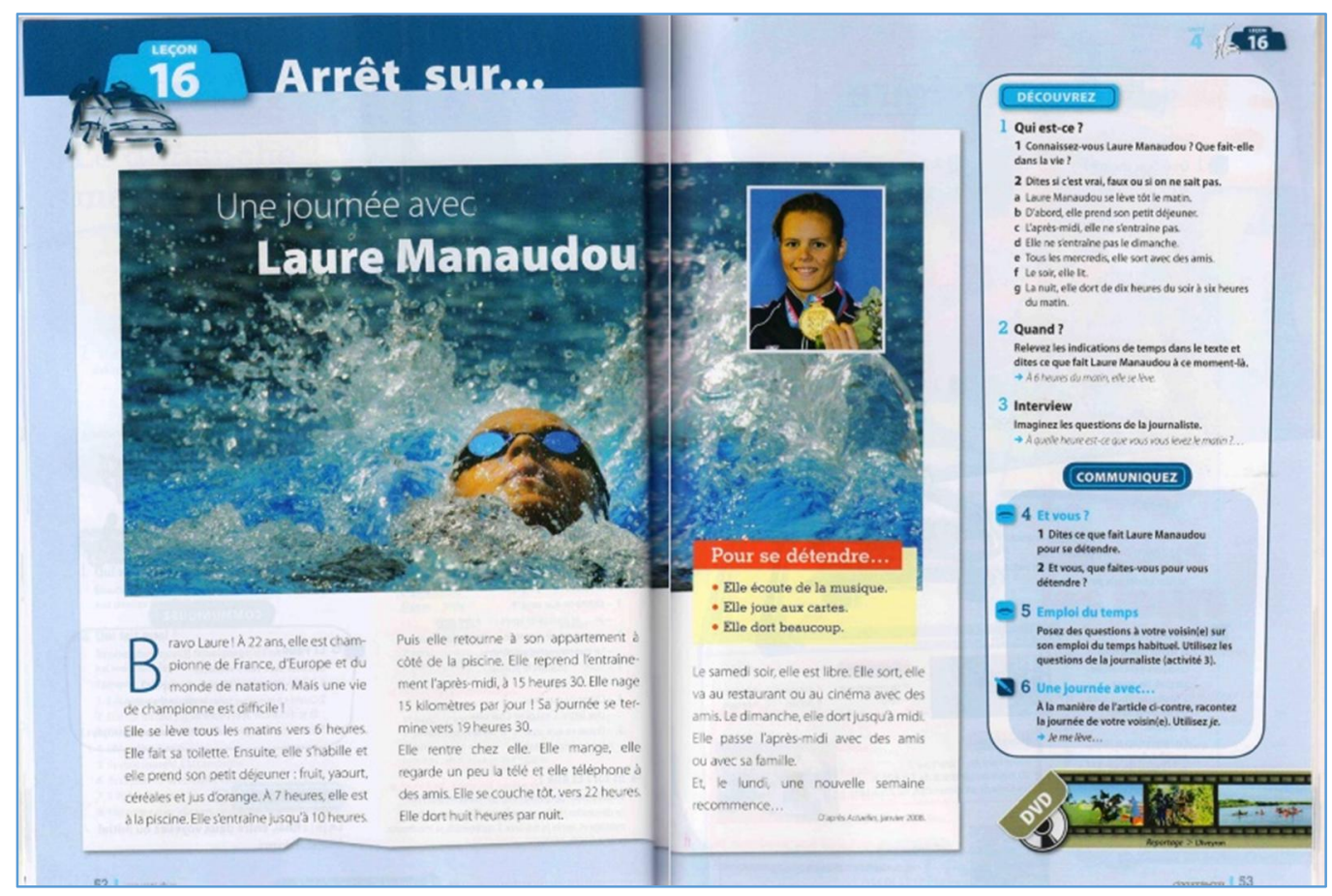

Görüntü 4. “Laure Manaudou’nun bir günü” Durağı (Le Nouveau Taxi 1, 2009: 52-53).

Kırklareli Üniversitesi, Fen Edebiyat Fakültesi, Türk Dili ve Edebiyatı Bölümü, Kayalı Kampüsü-Kırklareli/TÜRKIYYE e-posta: editor@rumelide.com
Address

Kurklareli University, Faculty of Arts and Sciences, Department of

Turkish Language and Literature, Kayalı Campus-Kırklareli/TURKEY

e-mail: editor@rumelide.com 
Beşinci ünitede kültürel öğeler yanı sıra dini öğelere de yer verildiği görülmektedir. Bu bağlamda beşinci ünite, "Mardi Gras” ve krep yapımı diyaloguyla başlamaktadır. İsa Mesih'in sunum ziyafeti ve Kutsal Bakire Meryem'in arıtılması ziyafeti olarak da bilinen "Chandeleur" gününü, (İsa'nın Tapınak'taki sunumunu anan gün) tanıtan etkinliğe yer verilmiştir. 18. derste kıyafet, gıda ve içecek alışveriş alışkanlıkları içerikli diyaloglar birbirini takip etmektedir. "Değerler, inanışlar ve tutumlar" da yer alan "kurumlar" temasında ise bir polis memurun aldığı ifade (un alibi) içerikli bir diyalog bulunmaktadır. 19. derste İtalya'da tatil yapan bir Fransız’n arkadaşına yazdığı kart postal göze çarpmaktadır. Ayrıca etkinliğin detaylarında öğrenenlerin kendi kültürlerinde yer alan turistik yerleri ve yapıları tanıtmaları istenmektedir. 20. derste Fransız Devriminin kutlandığı 14 Temmuz, Sevgililer günü, 1 Mayıs İşçi ve Emekçiler Bayramı, Noel, Fransız Müzik Bayramı, yllbaşı, vb. resmi ve dini bayramlardan bahsedilmektedir (Görüntü 3).

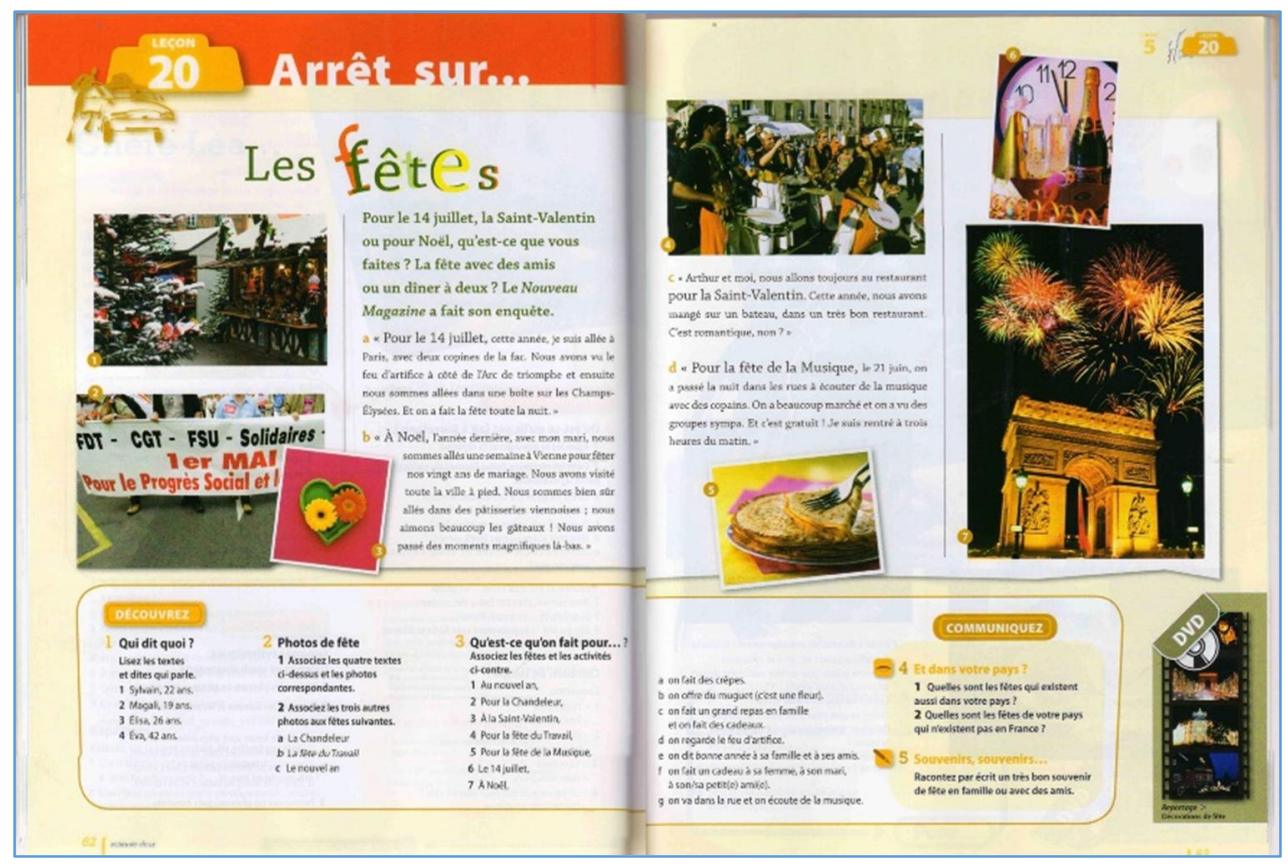

Görüntü 5. "Kutlamalar” Durağı (Le Nouveau Taxi 1, 2009: 62-63).

Altıncı ünitede restoranda, otelde ve trende nezaket kuralları açısından kişinin ne yapıp ne yapamayacağına değinen diyaloglara yer verilmiştir. 23. derste her kültürde önemli bir yere sahip olan doğum günü hazırlığı ve kutlaması, misafir karşılama, davetin nazik bir biçimde nasıl reddedilebileceği konuları işlenmiştir. Son derste ise, iş görüşmesinde ideal bir aday nasıl olunur konusuna değinilmiştir. Bu derste görgü kuralları üzerinde durulmuştur. Örneğin bir davete nasıl ve ne zaman gidileceği, arkadaşlarla yapılacak kutlama partisinin başarılı olabilmesi için yapılacaklar, yurt dışında başarılı bir tatilin nasıl gerçekleştirileceği gibi etkilere yer verilmiştir (Görüntü 6). 
Presentation of cultural items in French A 1 language level in foreign language French teaching coursebook "Le nouevau Taxi 1 methode de Français" / D. Demirkan (pp. 541-556)

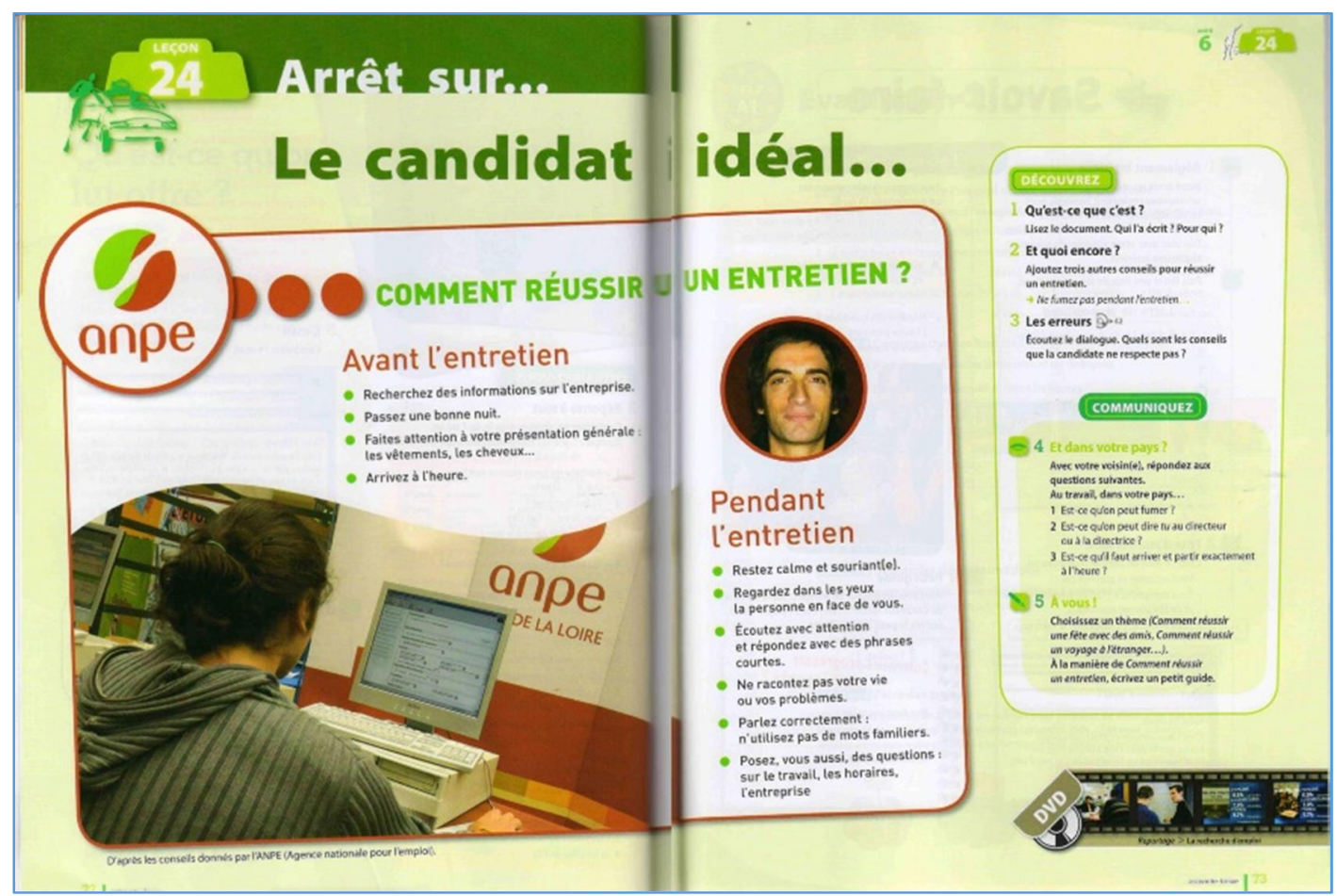

Görüntü 6. “İdeal aday” Durağı (Le Nouveau Taxi 1, 2009: 72-73).

Yedinci ünite günlük yaşam içerisinde gerçekleşen alışkanlıklar, spor, arkadaşlarla veya aileyle dışarı çıma, sevilen aktiviteler, tercihler işlenmiştir. Zevkler ve tercihleri ifade etme bolca örnekle tanıtılmıştır. Paris dışında kırsal hayat yaşam şartları bir diyalog yardımıyla ele alınmıştır. Şehirde ya da kırsal ortamında yaşamak, yalnız ya da arkadaşlarla yaşamak, pazardan ya da mağazadan alışveriş̧ yapmak, vb. gibi konuların avantajları ve dezavantajları verilmiştir. Fransızların tatil alışkanlıkları, bir ailenin tatile çıkmadan önceki son hazırlıkları ve farklı spor aktivitelerinin tanıtımı yapılmıştır. 


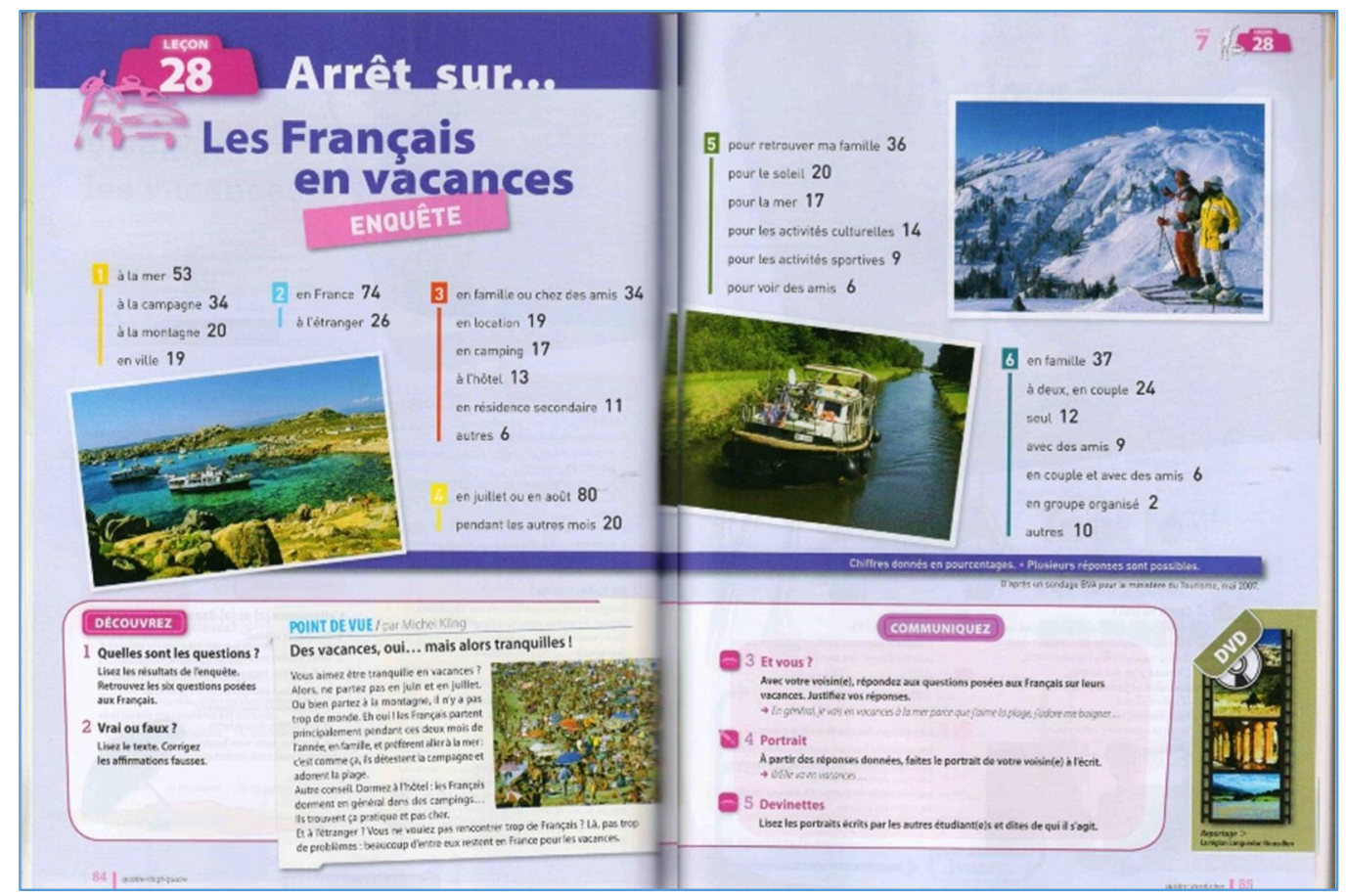

Görüntü 7. "Fransızlar tatilde” Dură̆ (Le Nouveau Taxi 1, 2009: 84-85).

Sekizinci ünitede sahne adı "Grand Corps Malade" olarak bilinen Fransız slam şair ve söz yazarı "Fabien Marsaud” ile yapılan röportaja yer verilmiştir. Aynı zamanda görsel destekleyici olarak da albüm kapă̆ resmi yer almaktadır. 30. derste otobanda meydana gelen bir kaza röportajı ve hava durumundan bahsedilmiştir. 31. Derste Fransız heykeltıraş François-Auguste Rodin'in kısa hayat hikâyesi ve Camille Claudel ile 1898 yılına kadar sürmüş olan aşkı anlatılmaktadır. Son derste Fransa'nın sembollerine yer verilmiştir. Örneğin kruvasan, Le Coq Sportif (1948'de Émile Camuset tarafından kurulan, ayakkabı, şort ve tişört başta olmak üzere çeşitli spor malzemeleri üreten şirket, Fransa'nın ulusal sembollerinden biri olan Galya horozundan gelen), Marianne Büstü, şampanya, Fransız moda haftasını temsilen "La Haute Couture", Paris, Fransa Bisiklet Turu, dünyaca bilinen Fransız ekmeği baget ve Fransız peyniri Camembert, TGV (Yüksek Hızlı Tren), Eyfel Kulesi ve tarihçesi, Citroën firmasının arabası (Görüntü 8) bunlardan birkaçıdır. Ayrıca Citroen'nin ilk arabasının tarihçesini konu edinen açıklama görsellerle desteklenmiştir. 
Presentation of cultural items in French A 1 language level in foreign language French teaching coursebook "Le nouevau Taxi 1 methode de Français" / D. Demirkan (pp. 541-556)

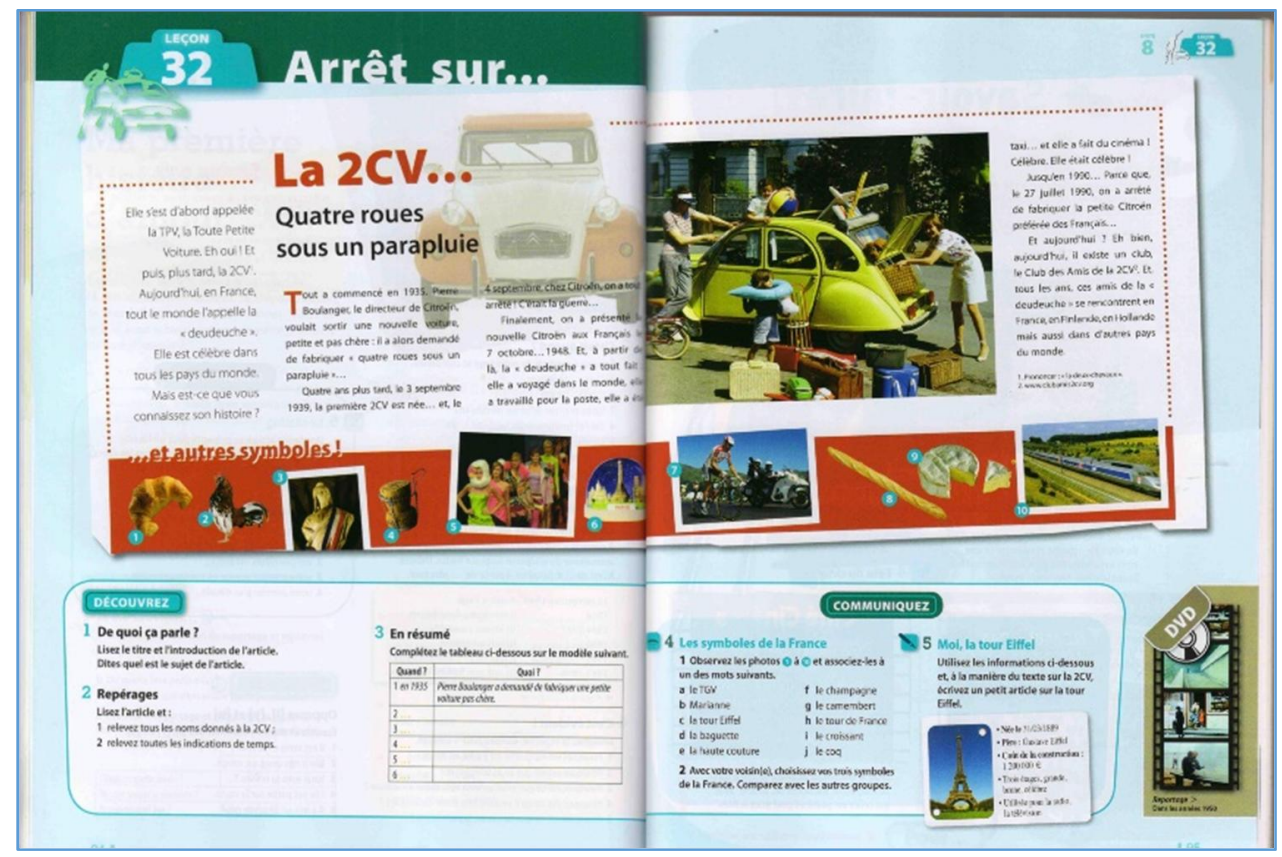

Görüntü 8. "Bir şemsiye altında dört teker... iki beygirlik Citroën” Durağı (Le Nouveau Taxi 1 2009: 94-95).

Dokuzuncu ünitede, Fransa haritasındaki çeşitli kentlerdeki hava durumunu işleyen bir diyalog bulunmaktadır. Diyalogun içeriğinde günlük konuşma sırasında öngörü, tahmin, olasılık ve kesinlik bildiren cümle kalıpları işlenmiştir. Randevu alma, iptal etme, kendisi ya da başka bir kişinin haftalık programını oluşturma, günlük, haftalık, aylık ya da yıllık programlar oluşturma üzerine diyaloglara yer verilmiştir. 34. derste, Fransız lise bitirme sınavı olan Bakalorya sınavı ele alınmıştır. Sosyal gelenekler içinde önemli yere sahip olan arkadaşlarla akşam yemeği programı yapma veya iptal etme konuları da yer almaktadır. 35. deste ev değiştirme, ev içi dekorasyon tercihleri, ev satın alma, vb. konuların geçtiği diyalog bulunmaktadır. Nezaket kurallarına uyarak bir teklifi reddetme cümle kalıpları ve son olarak ise Fransız ekmek çeşitleri ve mevsimlik/küçük yaz işleri arayışı konuları işlenmiştir. 


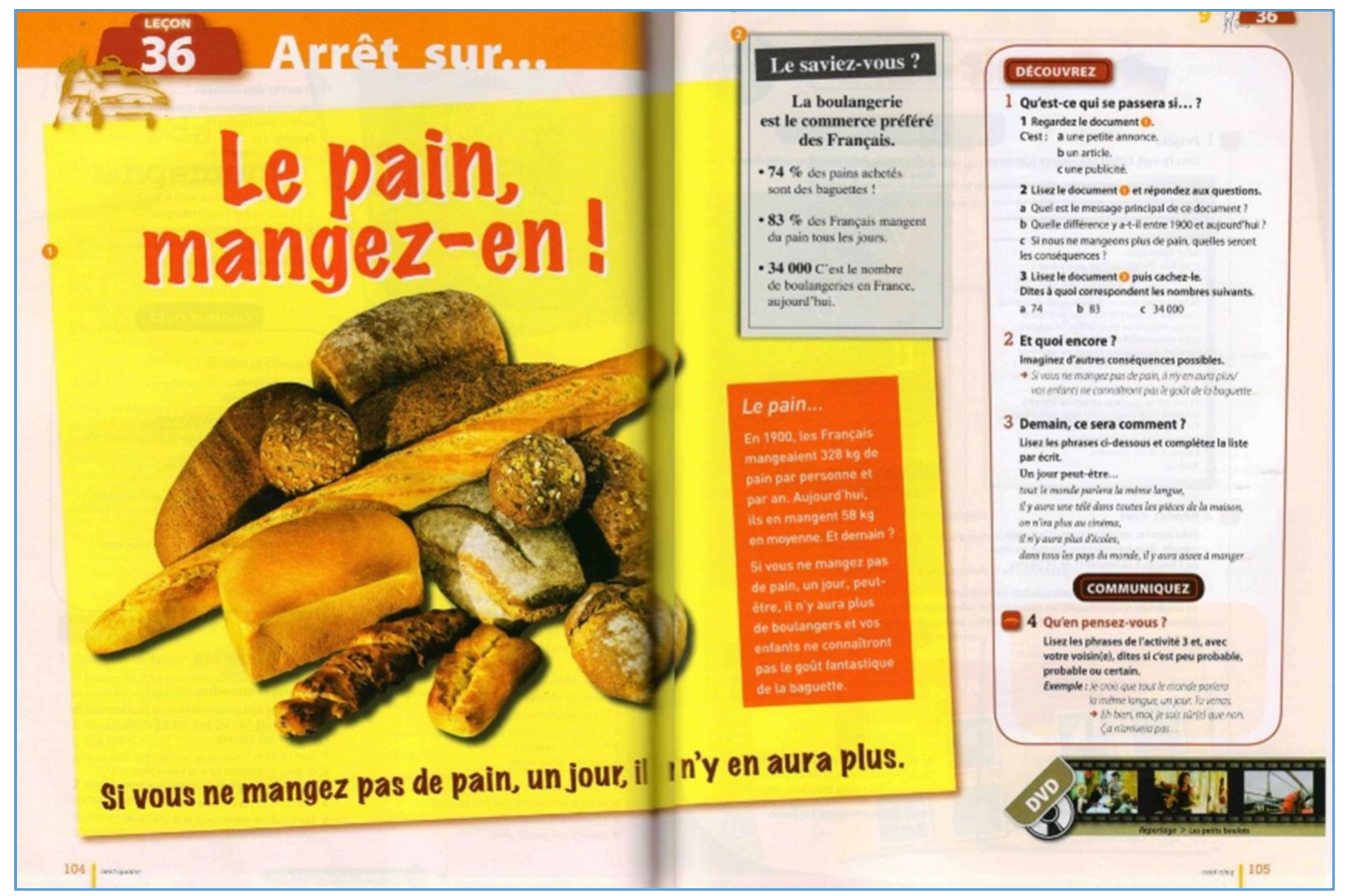

Görüntü 9. "Ekmekten yiyiniz” Durağı (Le Nouveau Taxi 1, 2009: 104-105).

Bilindiği gibi Fransız Mutfağı, dünya mutfakları içinde ilk üç mutfak arasında gösterilir ve geçmişten günümüze köklü bir kültürel değere sahip olan mutfaklardan biridir. Burada her kültürde önemli bir yere sahip olan "yiyecek alışkanlıkları" üzerinde durulmuştur. Hatta "baget ekmeği ve camembert peyniri” Fransız sofra kültürünün vazgeçilmezidir ve bu öğelere içerikte bolca değinilmeye çalışılmıştır. Görüntü 9’da Fransız Kültürünün dünyaca ünlü olan bu üçlüsünün ilki olan ekmekle giriş yapılmıştır.

Sonuç olarak, ders kitabı içeriğinde tüm kültürel öğeler yetişkin öğrenenlerin dil öğrenirken öğrenmelerine katkı sağlayacak biçimde olduğu görülmektedir. Ayrıca bu öğeler OBM'de de değinildiği gibi öğrenenlerin Fransızca öğrenmelerine olumlu katkı sağlayacak bir biçimde öğrenenlere sunulmuştur.

\section{Sonuç}

Kuşkusuzdur ki her dil, o dili konuşan toplum tarihinin ve kültürünün taşıyıcısıdır. Dillerin gelişmesi, insanları, varlıklarını daha iyi duyacakları entelektüel bir konuma getirince, bu gelişmenin aracı olan diller, öyle bir karakter kazanırlar ki, milletlerin karakteri onlarda, geleneklerde, törelerde ve olgularda olduğundan daha iyi anlaşılabilir (Akarsu, 1998:59). Dolayısıyla dil ve kültür kavramlarını birbirinden ayıramayız. Böylece, yabancı bir dil öğretiminde ya da öğreniminde, hedef dilin konuşulduğu toplumun kültürel öğelerini, tarihini, coğrafyasını, toplumsal davranış biçimlerini, olaylar karşısındaki tutumlarını kısacası dünyayı algılama biçimlerini öğrenmek şarttır. Bu çerçevede yabancı dil olarak öğretiminde başvurulan ders materyallerinden en önemlisi olan kitapların Diller İçin Avrupa Ortak Başvuru Metni ilkelerine bağlı olarak tasarlanmış olanlar arasında seçim yapması kaçınılmazdır.

Bu çalışmada, "Le nouveau Taxi 1 Méthode de Français" kitabı, Avrupa Konseyi tarafindan oluşturulmuş Diller İçin Avrupa Ortak Başvuru Metni "Sosyokültürel Bilgi” bölümünde betimlenmiş olan liste kapsamında incelenmiştir ve çalışmanın içeriğinde de ifade edildiği gibi, hedef kültür 
aktarımı etkin ve yeterli bir düzeyde gerçekleştirilmiştir. Üstelik kitabın sosyokültürel öğeleri resim, diyalog ve otantik belgelerle desteklenerek öğrenenlere sunulmuştur. Ayrıca gerek diyaloglarla gerekse metinlerle, kültürel öğelerin hangi bağlamda, hangi şartlarda kullanılması gerektiği de vurgulanmıştır. Bununla birlikte kitabın DVD-ROM’unda yer alan ek diyalog örnekleri yardımıyla Fransız toplumunda yer alan günlük yaşam biçimleri ve davranışları, çeşitli sosyal alışkanlıkları, kişiler arası ilişkileri, önemli tarihi ve kültürel öğeleri, törensel davranışları öğrenmeyi pekiştirecek nitelikte verilmiştir. Sonuç olarak, "Le nouveau Taxi 1 Méthode de Français" kitabı, albenili görselleri, güncel içeriğiyle ve çağdaş çizgileriyle öğrenenlerin A 1 düzeyi Fransızca dil öğrenmelerine önemli ölçüde katkı sağlayan bir biçimde tasarlanmış bir materyaledir.

\section{Kaynaklar}

Akarsu, B. (1998). Dil-Kültür Bağlantısı (3. Baskı).İstanbul: İnkılâp.

Aksan, D. (2003). Her Yönüyle Dil Ana Çizgileriyle Dil Bilim. Ankara: TDK.

Baydur, S.Y.(1999). Dil ve Kültür. İstanbul: Cumhuriyet.

Capelle, G. ve Menand, R. (2009). Le Nouveau Taxi1 Méthode de Français, Guide Pédagogique (Öğretmen Kılavuz Kitabı). Paris: Hachette.

Capelle, G. ve Menand, R. (2009). Le Nouveau Taxi1 Méthode de Français. Paris: Hachette Yayınları.

Conseil de l'Europe. CadreEuropéenCommun de Référencepourleslangues: apprendre, enseigner, évaluer (CECR). (www.coe.int/lang-CECR)

Diller İçin Avrupa Ortak Başvuru Metni: Öğrenme- Öğretme- Değerlendirme (http://digm.meb.gov.tr/uaorgutler/AK/cefr_Turkce.pdf)

Göçer, A. (2012). Dil-Kültür İlişkisi ve Etkileşimi Üzerine. Türk Dili, 729:50-57.

Güvenç, B. (1979), İnsan ve Kültür. İstanbul: Remzi Kitabevi.

Kaplan, M. (1982). Kültür ve Dil. İstanbul: Dergâh.

Kaptan, S. (1982). Bilimsel Araştırma Teknikleri ve İstatistik Yöntemleri. Ankara: Bilim.

Kasır, H.A. (1993). Kültür Bilinci. İstanbul: Denge.

Köksal, A. (1980). Dil ile Ekin. Ankara: TDK.

Kuş̧̧u, E. ve Karan, D. (2017). Yabancı Dil Öğretiminde Yöntemler Konusuna Genel Bir Bakış. The Journal of International Social Research. Cilt 10, Sayı 49.

Saussure, F.'den çev. Vardar, B. (1998). Genel Dilbilim Dersleri. İstanbul: Multilingual.

Türk Dil Kurumu, Büyük Türkçe Sözlük (http://www.tdk.gov.tr) Erişim tarihi: 23 Nisan 2020

Uygur, N. (1994). Dilin Gücü. İstanbul: Kabalcı.

Uygur, N. (2006). Kültür Kuramı. İstanbul: Yapı Kredi.

Ünalan, Ş. (2002). Dil ve Kültür. Ankara: Gazi Üniversitesi.

Ylldırım A. ve Şimşek H. (2013). Sosyal Bilimlerde Nitel Araştırma Yöntemleri. Ankara: Seçkin.

Yıldız, Ş. (2005). Dil Kültür İletişim ve Medya. Ankara: Sinemis. 